\title{
Design and field testing of the Fish-Eye lens for optical atmospheric observations
}

\author{
Ivan Syniavskyi $^{1}$, Yuriy Ivanov ${ }^{1}$, Sergey Chernous ${ }^{2}$ \\ and Fred Sigernes ${ }^{3}$ \\ ${ }^{1}$ Main Astronomical Observatory NAS of Ukraine \\ 27 Akademika Zabolotnoho str., Kiev, 03680, Ukraine \\ email: syn@mao.kiev.ua \\ ${ }^{2}$ Polar Geophysical Institute of the Kola Science Centre RAS, \\ 16 Fersman str. Apatity, Murmansk region, 184209, Russia \\ email: chernouss@pgia.ru \\ ${ }^{3}$ The University Centre in Svalbard (UNIS), \\ Longyearbyen, N-9171, Norway \\ email: fred.Sigernes@unis.no
}

\begin{abstract}
The Fish-Eye lens MAO-08 is intended for observations of weak extended objects (aurora, twilight and dawn phenomena, stratospheric clouds, etc.) in narrow spectral bands with variable passband filters VARISPEC and in white light. It is valuable for astronomical observation for the target - background problem when we need to estimate the spectral transparence of the atmosphere. Besides having high power this lens can be used for meteor observations. It has been tested during the winter field conditions.
\end{abstract}

Keywords. Fish-Eye lens; Interference Filter; Auroral Observations, Hyaline Observations.

\section{Introduction}

The Fish-Eye lens is most often used for observations of atmospheric phenomena such as aurora and nightglow (Elvey \& Stoffregen(1957), Lebedinsky (1961), Sandahl et al. (2008)). For observations of broad band, commercial fish-eye lenses can be used coupled to CCD detector. However, when it comes to obtaining narrow band images of auroral emissions lines with high temporal resolution, the task of researchers is much more complicated. The filters require to be collimated light in order to obtain optimum bandpass. A standard technique is to use an telecentric lens system (Mende et al. (1977), Sandahl et al. (2008)). The MAO-08 lens does not use this system and based on calculations as a whole.

\section{Main Parameters}

The ultra wide-angle lens MAO-08 can be used with interference filters, variable spectral bandwidth filters (VARISPEC), or without any filters (white light). Figure 1 shows the optical diagram of the lens. The first part converts the $180^{\circ}$ field of view (FOV) to a narrow beam of $6^{\circ}$, where interference filters may be inserted. The back part focuses the collimated light onto the detector plane. The design is compact with unique optical characteristics. The basic technical data:

- FOV: 180 degrees;

- F/value: 0.82 ;

- Spectral range: $430-750 \mathrm{~nm}$; 
- Resolution: center - $100 \mathrm{l} / \mathrm{mm}$; edge - $70 \mathrm{l} / \mathrm{mm}$;

- Dimensions (with covers): length $235 \mathrm{~mm}$ and diameter $103 \mathrm{~mm}$

\section{Field testing}

Lens tests in field conditions have confirmed high quality of images. (Fig. 2a) is image of the ray auroral arc, obtained at Barentsburg in white light. There are a plenty of constellations and stars in this figure and even the Milky Way is seen. (Fig. 2b) shows the weak auroral folds in the emission at $557.7 \mathrm{~nm}$, obtained with narrow-band interference filter $(\Delta \lambda \sim 2 \mathrm{~nm})$.

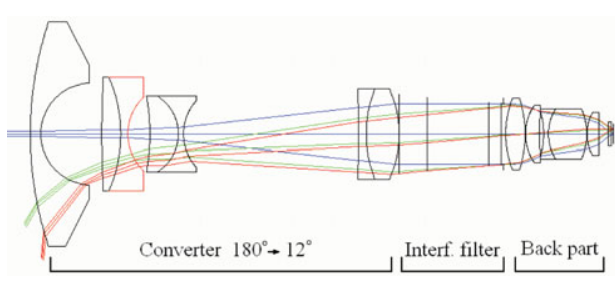

Figure 1. Layout of the MAO-08 lens.

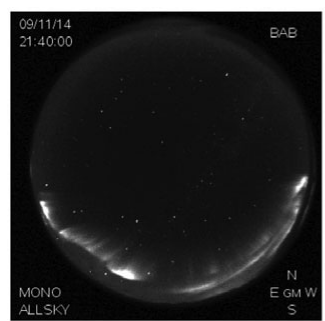

a

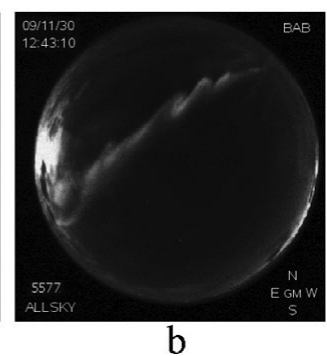

$\mathrm{b}$

Figure 2. All-sky images of aurora: a) in white light, b) at $\lambda \sim 557.7 \mathrm{~nm}$.

A first season of observations was spent during the period November 2011 - April 2012 in the Kjell Henriksen Observatory (KHO) in Svalbard located at the archipelago Svalbard $1000 \mathrm{~km}$ north of mainland Norway $\left(78^{\circ} \mathrm{N}, 16^{\circ} \mathrm{E}\right)$, and Barensburg research Station, PGI $\left(78.093^{\circ} \mathrm{N}, 14.208^{\circ} \mathrm{E}\right)$.

\section{Conclusion}

The MAO-08 lens has a large aperture, which exceeds this parameter of the other lenses for auroral research. It allows filters to be inserted into the lens. Pointed out is the possibility of obtaining simultaneously two images in two emissions of the same aurora by the single CCD camera.

\section{Acknowlegements}

This work was financially supported by The Research Council of Norway through the project named: Norwegian and Russian Upper Atmosphere Co-operation on Svalbard part 2 \# 196173 / S30 (NORUSCA2).

\section{References}

Elvey, S. T. \& Stoffregen, W. 1957, Ann. Int. Geophys. Year, 5, 117

Mende, S. B., Eather, R. H., \& Aamodt, E. K. 1977, App.Optics, 16, 1691

Lebedinsky, A. I. 1961, Ann. Int. Geophys. Year, 11, 133

Sandahl, I., Sergienko, T., \& Brandstorm, U. 2008, JASTP, 70, 2275 